\title{
Effect of Ceramic Aggregate and Fly ash in Normal Strength Concrete
}

\author{
Ganesan Nagalingam
}

\begin{abstract}
In this study, full and partial replacement of stone aggregate by ceramic insulator scrap and partial replacement of cement by fly ash has been done in order to enhance economy in construction. More once, the solution of disposal of wasting from ceramic insulator manufacturing company and thermal power plant is also achieved. Further various mechanical properties of ceramic insulator scrap such as crushing value, impact value, abrasion value, specific gravity, sieve analysis and water absorption has been studied and obtained to make the study fruitful. Concrete of grade M15 is used to study the compressive strength properties of stone and ceramic aggregates. Replacement of stone aggregates by ceramic aggregates has been done in stages starting from $0 \%$ to $100 \%$ each stage possessing the variation of $10 \%$ and in all the specimens $30 \%$ of cement is replaced by $35 \%$ of fly ash. Six number of cube samples are cast for each variation and the compressive strength of the same have been obtained at 7, 28 and 56 days of age. Totally 216 cubes are cast and tested for compression. It is found that the optimum percentage at which the stone aggregate can be replaced by ceramic aggregates is $50 \%$ and $30 \%$ of cement can be replaced by $35 \%$ fly ash.
\end{abstract}

Keywords : Ceramic aggregate, compressive strength, fly ash, stone aggregate,

\section{INTRODUCTION}

Construction materials are the main concern of developing a country's infrastructure. The industrial waste materials which are used as building materials not only minimize the constriction cost but also improve the economic condition of the country. Electricity is one of the basic inputs required for development of any country and not even in a single field or industry can function without adequate supply of power. Coal is the main source of power in India owing to large reserves of power grade coal. Due to low calorific value and high ash content (upto 40\%) of Indian coals, these produce massive amounts of coal ash to the tune of 5-6 tonnes per MW per day. About 40-50 million tonnes of coal ash is being generated in India. Efforts have been made to utilize the ash. However, these have met with only sporadic success and overall ash utilization level in India is reported to be as low as $2-3 \%$ only. Fly ash is composed of a large silica content (upto 60-70 percent) which acts at the beginning as an inert material. At later stage the pozzolanic action starts and the siliceous portion reacts with calcium hydroxide liberated from Portland cement to form final stable substance. Many

Revised Manuscript Received on December 5, 2019

* Correspondence Author

"Ganesan Nagalingam, Department of Civil Engineering, Kalasalingam Academy of Research and Education, Krishnankoil, Virudhunagar District, Tamilnadu .Email: civilganesan139@gmail.com research works prove that fly ash increases the workability, reduces bleeding and segregation, reduces the heat of hydration and low permeability.[1]

Similarly, in a ceramic insulator industry, there is a mass failure of $30-50 \%$ of the total production due to improper mixing of raw materials, excess water, improper drying, too much of heating etc. This waste is not recycled in any form and also it occupies $25 \%$ of the total area of the industry. These ceramic insulation scraps are initially broken into pieces with sledge hammer and then fed into a jaw crusher which in turn breaks them into the required size of $20 \mathrm{~mm}$. The ceramic aggregates are sharp and angular in shape which resembles that of the natural coarse aggregates. Further the ceramic aggregate properties such as aggregate crushing value, abrasion value etc are equivalent or replacement to stone aggregate.[2] So here an attempt is made to use fly ash as a replacement of cement and ceramic insulator scrap as a replacement of coarse aggregate to utilize these waste materials as a building material [3]

\section{MATERIALS}

\section{A. Cement}

Ordinary Portland cement of 43 Grade manufactured by $\mathrm{M} / \mathrm{s}$ Chettinadu cement confirming to I.S. 8112-1989 specifications. It is made use of casting the specimen, the cement used is taken from a single lot.[4]

\section{B. Fly ash}

Fly ash of Class C type obtained from Neyveli Lignite Corporation, Thermal power plant $\mathrm{I}$ is used in this experimental investigation and the physical and chemical analysis of Lignite ashes are carried out at Neyveli Lignite Corporation Ltd.

\section{Fine aggregate}

The fine aggregate used is clean dry river sand; the sand is sieved to remove all the pebbles and impurities in the soil. The river sand confirming to Zone 2 of IS 382- 2016 after sieving through $2.36 \mathrm{~mm}$ sieve is used as fine aggregate. The specific gravity of the fine aggregate used in this study is 2.623 and fineness modulus is 2.264 [5]

\section{Stone aggregate}

Hard granite broken stone is used as coarse aggregate. The maximum size of the aggregate is $20 \mathrm{~mm}$. This stone aggregate confirms to IS: 383 -1970. The specific gravity of the stone aggregate is 2.781 and fineness modulus is 7.154.

Published By: 


\section{E. Ceramic aggregate}

Broken ceramic are used in this study as a coarse aggregate to replace hard broken stone. (Fig 1) Maximum size of ceramic aggregate is $20 \mathrm{~mm}$. The specific gravity of the ceramic aggregate is 2.43 and fineness modulus is 7.70 .

\section{F. Water}

Potable water of good quality is used for mixing the concrete. It is free from alkalis and organic matters.

\section{EXPERIMENTAL WORK}

\section{A. Mix proportion for experimental work}

The mix design for M15 grade concrete is prepared as per the Indian Standard of mix design IS 10262-2009 and the materials used in this work are listed in Table 1 below.[6]
Table- I: Materials for the experimental work

\begin{tabular}{|c|c|c|c|c|}
\hline Materials & Cement & FA & CA & Water \\
\hline $\begin{array}{c}\text { Quantity } \\
\left(\mathrm{kg} / \mathrm{m}^{3}\right)\end{array}$ & 336.11 & 615.27 & & \\
\hline
\end{tabular}

B. Mix ID for various combinations of stone aggregates and ceramic aggregates

The various combinations of stone aggregate and ceramic aggregates used for preparing the cube specimens are listed in the Table 2 below.

Table 2: Specimens and Mix ID for the experimental work

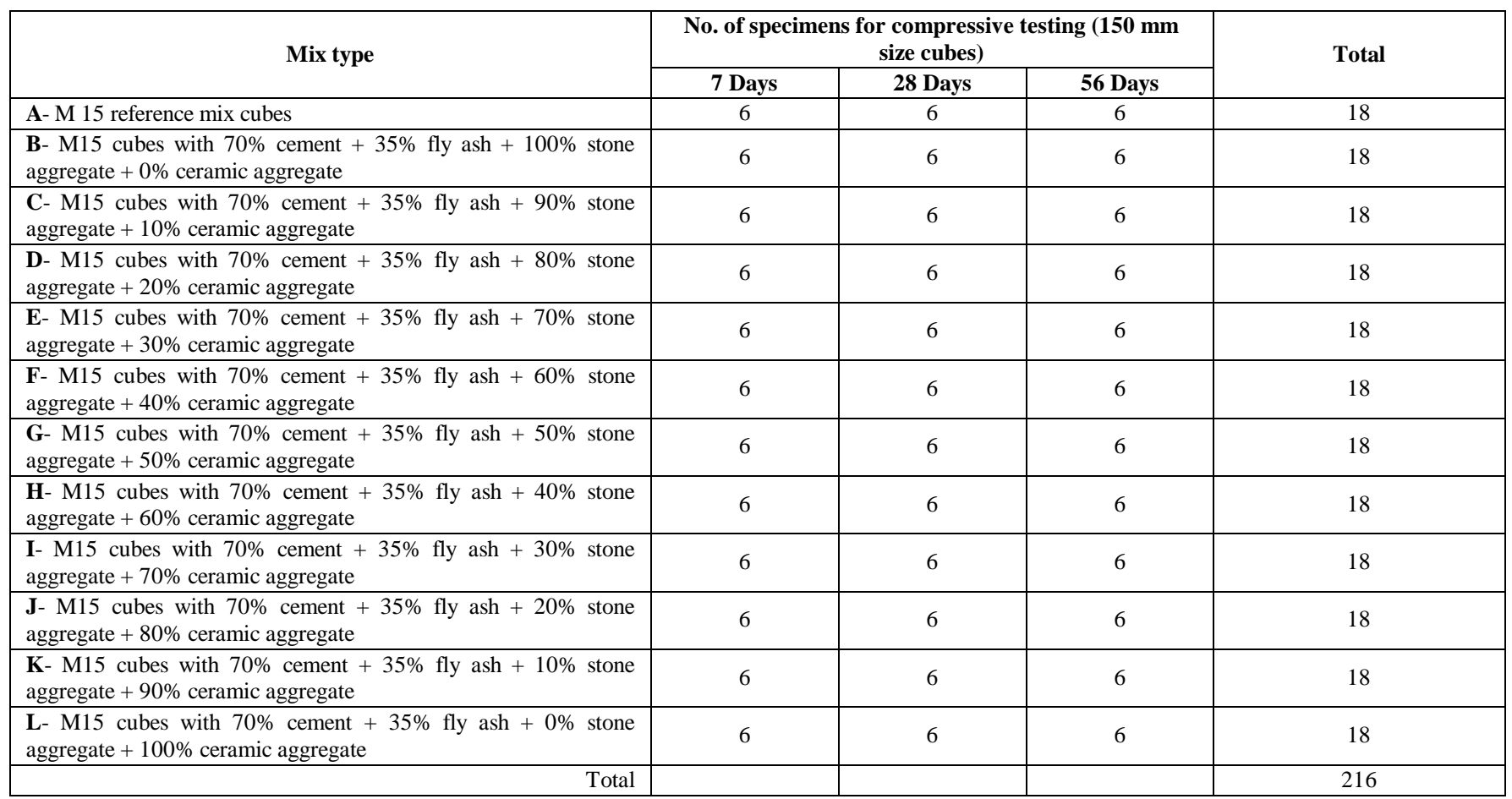

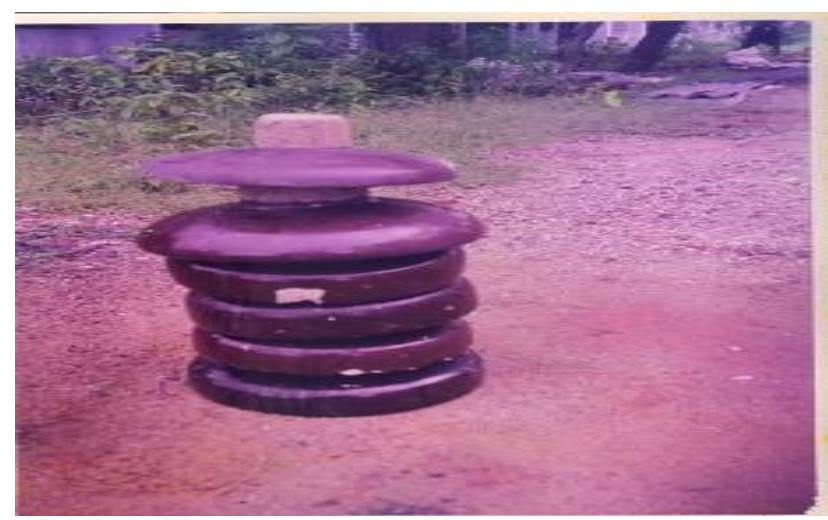

Fig.1. Ceramic Insulator

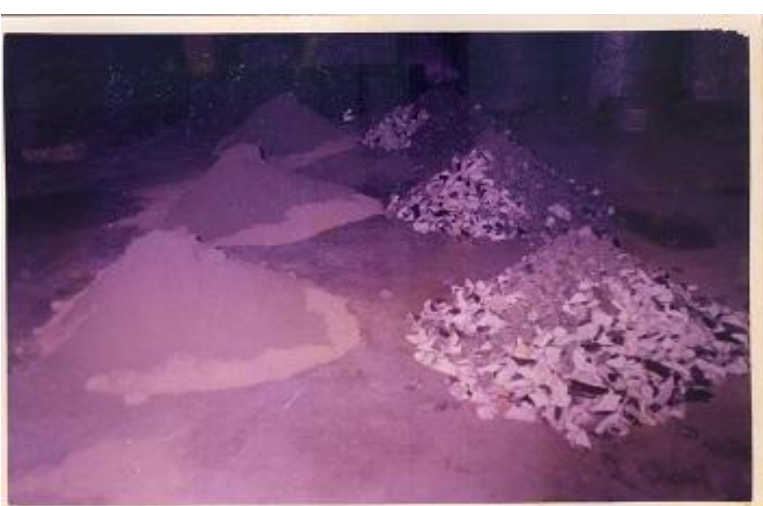

Fig.2. Materials for mixing

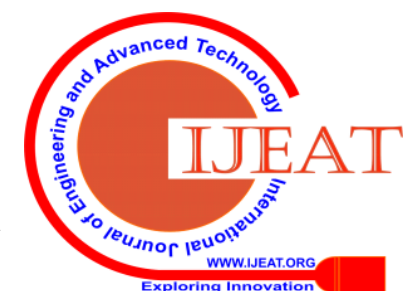




\section{Compression test}

Initially cubes of size $150 \mathrm{~mm} \times 150 \mathrm{~mm} \times 150 \mathrm{~mm}$ are cast for the controlled mix (A) .Then in the controlled mix, cement is replaced by fly ash by various percentages. The cubes are subjected to compression test and finally it is concluded that $30 \%$ of cement can be replaced by $35 \%$ of fly ash and this is optimized. Then the stone aggregate is replaced by ceramic aggregate at $10 \%$ variations as shown in the Table 2 above. In all the specimens, $30 \%$ of cement is replaced by $35 \%$ fly ash. Six cube specimens of size $150 \mathrm{~mm} x$
$150 \mathrm{~mm} \times 150 \mathrm{~mm}$ are cast for all the mix combinations mentioned in the Table 2 above for testing the specimens at 7 , 28 and 56 days. A total of 216 cubes are cast and tested for compression as per the code provisions [7,8] after the required days of curing. (Fig 3) The average compressive strength values for all the testing days are given in the Table 3.The testing arrangement for compression strength is shown in Fig 4.

Table 3: Compressive strength test results

\begin{tabular}{|c|c|c|c|c|c|c|c|c|c|c|c|c|}
\hline \multicolumn{10}{|c|}{ Average Compressive strength in N/mm $\mathbf{~}^{2}$} \\
\hline Testing Days & A & B & C & D & E & F & G & H & I & J & K & L \\
\hline $\mathbf{7}$ & 16.59 & 14 & 13.22 & 11.41 & 13.33 & 14.78 & 16.52 & 13.19 & 12.41 & 15.41 & 14.81 & 15.85 \\
\hline 28 & 29.78 & 25.93 & 24 & 22.22 & 22.78 & 26.48 & 26.93 & 24.67 & 19.3 & 22.07 & 21.18 & 22.74 \\
\hline 56 & 34.15 & 27.7 & 24.3 & 22.67 & 23.48 & 28.74 & 29.63 & 25.04 & 19.78 & 23.26 & 21.63 & 23.93 \\
\hline
\end{tabular}

\section{TEST RESULTS AND DISCUSSION}

\section{A. General}

In this scope of study, the experimental programme is divided into three parts for discussing the compressive strength of M15 grade concrete cubes at 7 days, 28 days and 56 days with fly ash, stone aggregate and ceramic aggregate. The compressive strength of cubes containing flyash, stone aggregate and ceramic aggregate obtained at 7, 28 and 56 days are compared with M15 controlled mix specimens

\section{B. Discussion on 7 days compressive strength results}

At the age of 7 days, the compressive strength of cubes with $100 \%$ stone aggregate without fly ash is $16.59 \mathrm{MPa}$. Then in M15 grade of concrete, stone aggregate is replaced by ceramic aggregate from $0 \%$ to $100 \%$ and $30 \%$ cement is replaced by $35 \%$ of fly ash in all specimens except in controlled mix specimens.

In this percentage of replacement, the compressive strength varies from 11.41 $\mathrm{MPa}$ to $16.52 \mathrm{MPa}$ and the percentage of strength varies from $68.78 \%$ to $99.58 \%$. In this percent of replacement of fly ash and ceramic aggregate, 50\% replacement (i.e.) concrete with $30 \%$ of cement replaced by $35 \%$ fly ash and $50 \%$ stone aggregate replaced by $50 \%$ of ceramic aggregate has a strength nearly equal to that of stone aggregate concrete specimens without fly ash (i.e.) M15 controlled specimens and it is observed that the optimum percentage of replacement of stone aggregate by ceramic aggregate is $50 \%$ for early strength. The comparison of 7 days compressive strength results are shown in Fig 5.

\section{Discussion on 28 days compressive strength results}

At the age of 28 days, the compressive strength of cubes with $100 \%$ stone aggregate without flyash (i.e.) M15 controlled specimens is about 29.78 MPa. Here also, in M15 grade concrete, stone aggregate is replaced by ceramic aggregate from $0 \%$ to $100 \%$ and $30 \%$ of cement is replaced by $35 \%$ of fly ash in all specimens except in controlled mix specimens.

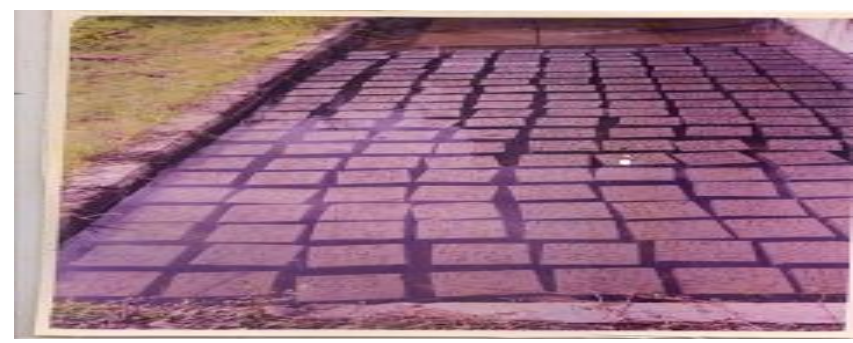

Fig.3. Curing of specimens

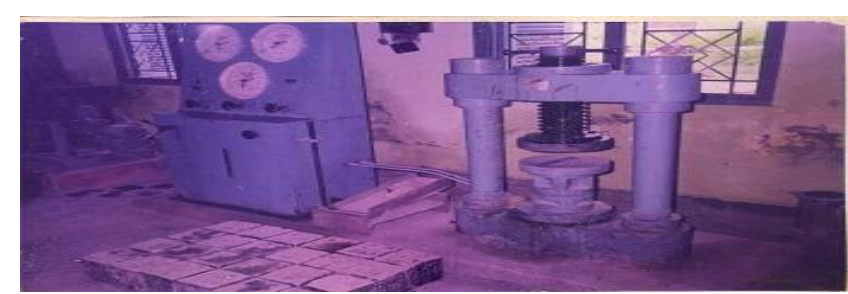

Fig.4. Testing arrangement

7 DAYS (AVERAGE) COMPRESSIVE STRENGTH (N/mm2)

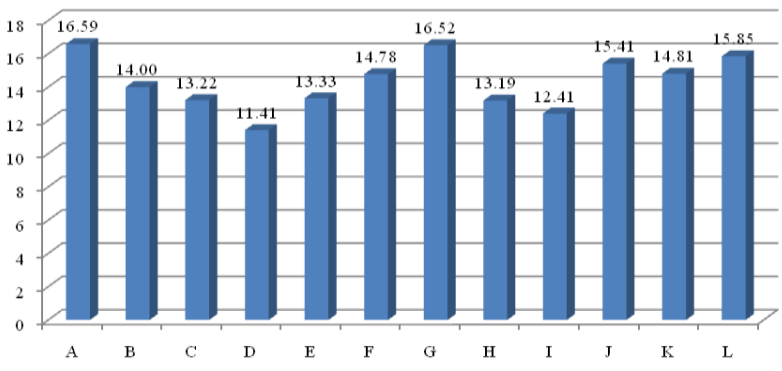

Fig.5. Comparison of 7 Days Compressive test results

In this percentage of replacement, the compressive strength of cubes varies from 19.30 MPa to 26.93 $\mathrm{MPa}$ and the percentage of strength varies from $64.81 \%$ to $90.43 \%$. In this percentage of replacement of fly ash and ceramic aggregate, $50 \%$ replacement (i.e.) concrete with $30 \%$ of cement replaced by $35 \%$ fly ash and $50 \%$ of stone aggregate replaced by $50 \%$ of ceramic aggregate has strength nearly equal to that of stone aggregate concrete specimens without fly ash (i.e.) M15 controlled specimens and it is also observed

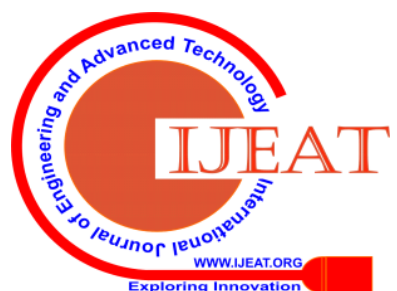


that the optimum percentage of replacement of stone aggregate by ceramic aggregate is $50 \%$. The comparison of 28 days compressive strength results are shown in Fig 6.

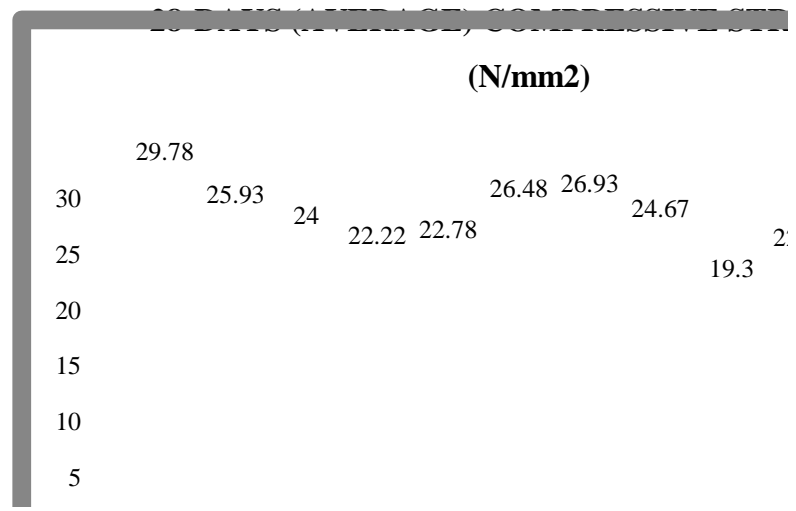

Fig.6. Comparison of 28 Days Compressive test results

\section{Discussion on 56 days compressive strength results}

At the age of 56 days, the compressive strength of cubes with $100 \%$ stone aggregate without flyash (i.e.) M15 controlled specimens is about 34.15 MPa. When the cement is replaced by flyash and stone aggregate replaced by ceramic aggregates as said in the earlier two cases, the compressive strength of cubes varies from 19.78 MPa to 29,63 MPa and the percentage of strength varies from $57.92 \%$ to $86.76 \%$. In these percentage replacements, $50 \%$ replacement shows the strength nearer to the controlled mix cubes and it is clear that, $50 \%$ replacement of stone aggregate is optimum. The comparison of 56 days compressive strength results are shown in Fig 7.

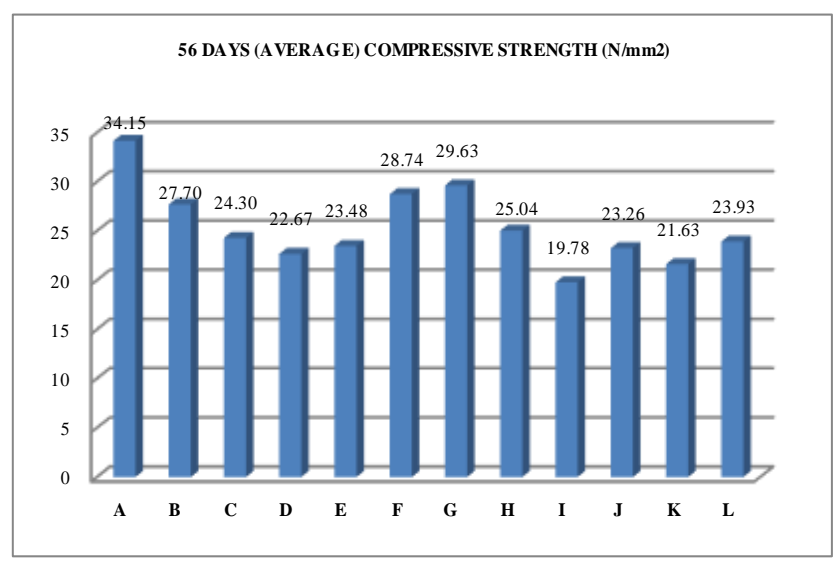

Fig.7. Comparison of 56 Days Compressive test results

\section{CONCLUSION}

(i) From the experimental programme, it has been observed that the optimum percentage at which the stone aggregate can be replaced by ceramic aggregates is $50 \%$ and $30 \%$ of cement can be replaced by $35 \%$ fly ash.

(ii) In this study, concrete containing fly ash and ceramic aggregate gained early age strength nearly equal to that of concrete containing stone aggregate without flyash. (iii) In this study, the rate of development of strength of concrete containing ceramic aggregate and fly ash is same as concrete containing stone aggregate without fly ash.

(iv) Above $50 \%$ replacement of stone aggregate shows strength reduction in 7days, 28 days and 56 days.

(v) Since fly ash and ceramic aggregates are industrial wastes and can be obtained at free of cost and plenty, the replacement of stone aggregate by ceramic aggregate and cement by fly ash proves to be more economical than that of concrete containing stone aggregate without fly ash.

\section{REFERENCES}

1. RM Senthamarai, P Devadas Manoharan "Concrete with ceramic waste aggregate", Cement and Concrete Composites, 2005, pp 910-913,27

2. A.S.Brito J.de, Pereira, J.R.Correia, Mechanical behaviour of non-structural concrete made with recycled ceramic aggregates", Cement and Concrete Composites, 2005,pp 429-433

3. Weihua Jin, Christian Meyer and Stephen Baxter, "Glasscrete- Concrete with Glass Aggregate”, ACI Materials Journal, 2000, pp 208-213

4. IS 8112-1989 Specification for 43 Grade Ordinary Portland Cement, Bureau of Indian Standards, New Delhi.

5. IS 383-1970- Specification for coarse and fine aggregates from natural sources for concrete, Bureau of Indian Standards, New Delhi, India

6. IS 10262-2009, Indian Standard Concrete mix proportioning-Guidelines (First revision), Bureau of Indian Standards, New Delhi, India

7. IS 2386 (Part I-VIII)-1960, Indian Standards method of testing of concrete, (First revision), Bureau of Indian Standards, New Delhi, India

8. IS 516-1959-Method of tests for strength of concrete, Bureau of IndianStandards, New Delhi, India

\section{AUTHORS PROFILE}

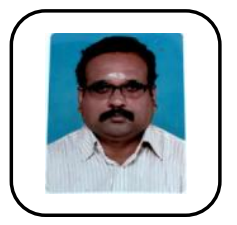

etc.
Ganesan Nagalingam completed his UG in Civil Engg. from A.C.Tech, Karaikudi and PG in Structural Engineering from Annamalai University, and pursuing his $\mathrm{PhD}$ from Kalasalingam Academy of Research and Education. He has more than twenty five years of experience in teaching and industry. His areas of research include geopolymer concrete, high performance concrete 